\title{
Successful Endovascular Management of Large Traumatic Anterior Tibial Artery Pseudoaneurysm
}

\author{
Vishal N. Bakare ${ }^{1}$, Shubhasish Pattnaik ${ }^{2}$ \\ ${ }^{1}$ Faculty, Department of Interventional Radiology, Dr. D. Y. Patil Medical College and Hospital, Pimpri, \\ Maharashtra, India \\ ${ }^{2}$ Department of Interventional Radiology, Dr. D. Y. Patil Medical College and Hospital, Pimpri, Maharashtra, \\ India \\ Corresponding Author: Vishal N. Bakare
}

\section{ABSTRACT}

Traumatic tibial artery pseudoaneurysms are rare entities. There are various treatment modalities described in literature. We describe a case of traumatic anterior tibial artery pseudoaneurysm successfully managed by Endovascular microcoil embolisation.

Keywords: Anterior Tibial Artery

Pseudoaneurysm, Trauma, Endovascular

Management, Microcoil Embolisation

\section{INTRODUCTION}

Literature has described many cases of orthopedic procedure related anterior tibial artery pseudoaneurysms ${ }^{(\mathbf{1})}$. However, traumatic tibial artery pseudoaneurysms are rare. These pseudoaneurysms are associated with significant morbidity and require prompt management. Traditionally, open surgery was the mainstay of management in cases of Tibial artery pseudoaneurysms ${ }^{(2)}$. There are many treatment options mentioned in literature such as ligation of the parent artery, direct repair of pseudoaneurysm, vein graft interposition, endovascular coiling or thrombin embolization, covered stent graft placement (3).

We report a case of large anterior tibial artery (ATA) pseudoaneurysm after blunt trauma due to road traffic accident in a middle aged gentleman which was successfully managed with endovascular technique.

\section{CASE REPORT}

A middle aged gentleman came to Interventional Radiology OPD with history of road traffic accident 4 days ago which was followed by swelling on dorsal aspect of his right foot.

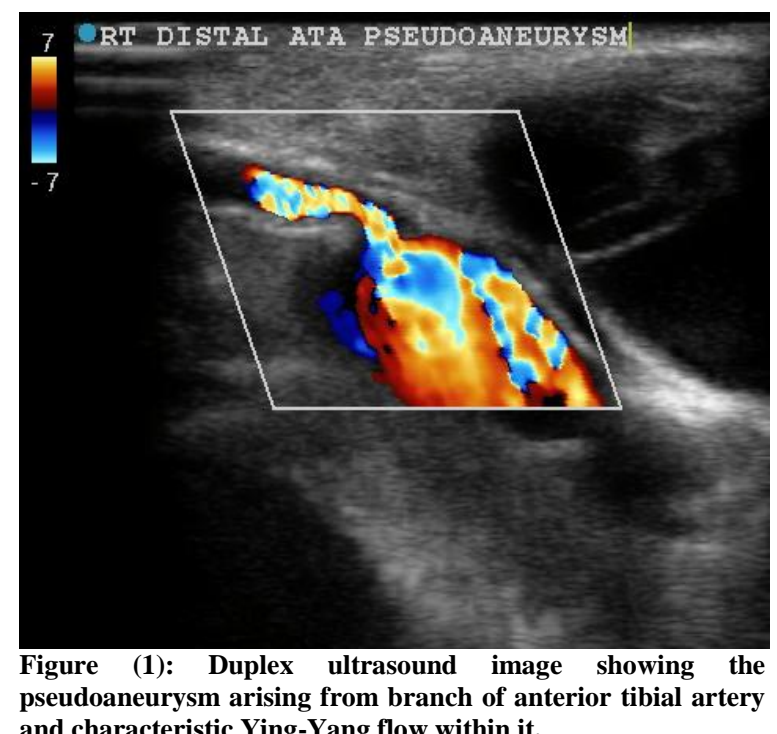
pseudoaneurysm arising from branch of anterior tibial artery and characteristic Ying-Yang flow within it.

On examination, the swelling was pulsatile with no obvious discoloration of overlying skin. The ankle \& toe movements were restricted causing walking difficulty for the patient. On palpation, it was soft to touch, pulsatile and painless. Clinically the likely diagnosis was of traumatic pseudoaneurysm of tibial artery which was confirmed by Duplex ultrasound. It revealed large pseudoaneurysm arising from anterior tibial artery branch. There was characteristic yin-yang flow within the sac (Figure 1). 
Being large in size, the lesion was causing pressure effect on adjacent structures and distal vascular steal phenomenon due to which the toes were cold on touch as compared to other side. Considering all the available treatment options for this patient, we decided to go with endovascular embolisation of the parent artery. We ensured the patency and blood flow in the posterior tibial and peroneal arteries on Duplex ultrasound, so as to maintain the foot perfusion post embolisation.

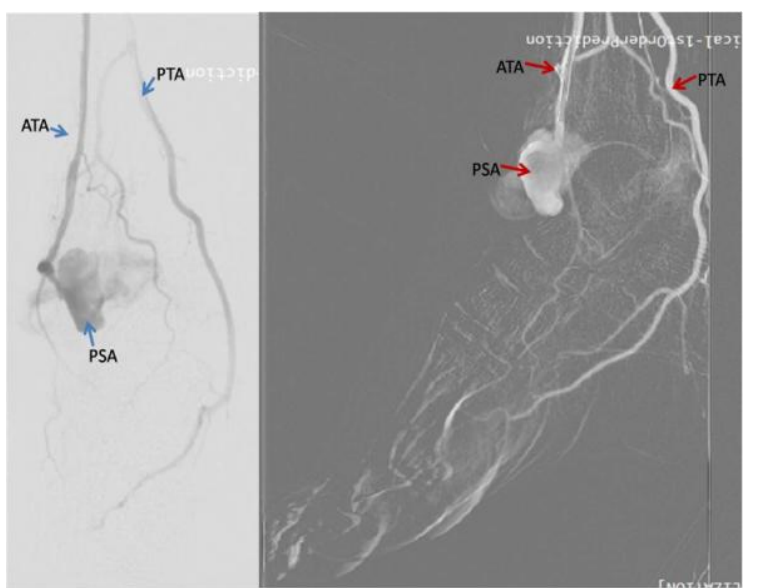

Figure (2) Diagnostic Angiogram showing the Anterior tibial artery (ATA), Posterior tibial artery (PTA) and pseudoaneurysm (PSA) arising from branch of ATA.

Under local anesthesia and ultrasound guidance, antegrade right femoral arterial puncture was done and $5 \mathrm{~F}$ arterial sheath introduced. The tibial angiograms revealed pseudoaneurysm arising from branch of ATA just below the ankle and good flow in the posterior tibial and peroneal arteries (Figure 2). The arterial plantar arches were well opacified. Taking a $4 \mathrm{~F}$ catheter (Head Hunter H1, Cordis) and guidewire (Terumo, Angled tip, 0.035" 150 $\mathrm{cm}$ ), selective cannulation of the distal ATA was done. On roadmap guidance, microcatheter cannulation (Progreat 2.7F) of the branch leading to the pseudoaneurysm was done. Contrast angiograms confirmed the large patent sac (Figure 3). Embolisation of this branch artery was done using Microcoils (Cook, Hilal Embolisation coils 18-3.0-3). Repeat check angiogram was done keeping the catheter tip in the popliteal artery which revealed distal refilling of the pseudoaneurysm sac from the plantar arch. Under ultrasound guidance, this small branch was cannulated with needle (Chiba 21G, $10 \mathrm{~cm}$ ) and microcoil embolisation done (Cook, Hilal Embolisation coils 18-2.0-2) (Figure 4). Repeat check angiogram form catheter tip in the popliteal artery revealed complete exclusion of the pseudoaneurysm sac from circulation and patient ATA, PTA and peroneal arteries with good opacification of the plantar arches (Figure 5). On day of discharge, the patency of the tibial arteries was reconfirmed on clinical examination \& Duplex ultrasound. Thus our procedure was successful.

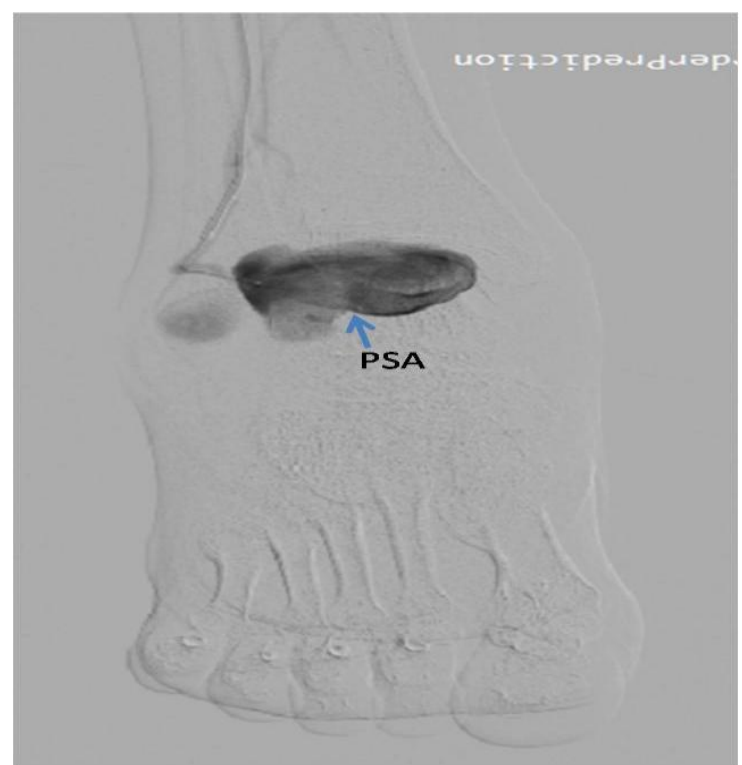

Figure (3) Diagnostic angiogram after superselective cannulation of the branch of ATA leading to pseudoaneurysm sac using microcatheter.

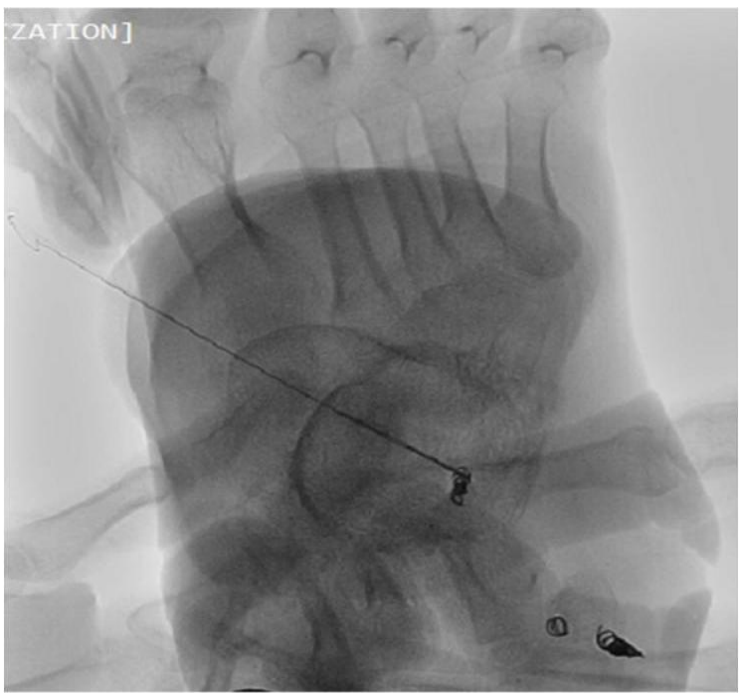

Figure (4) Percutaneous microcoil embolisation of distal feeding artery of the pseudoaneurysm sac through percutaneous ultrasound guided needle puncture. 


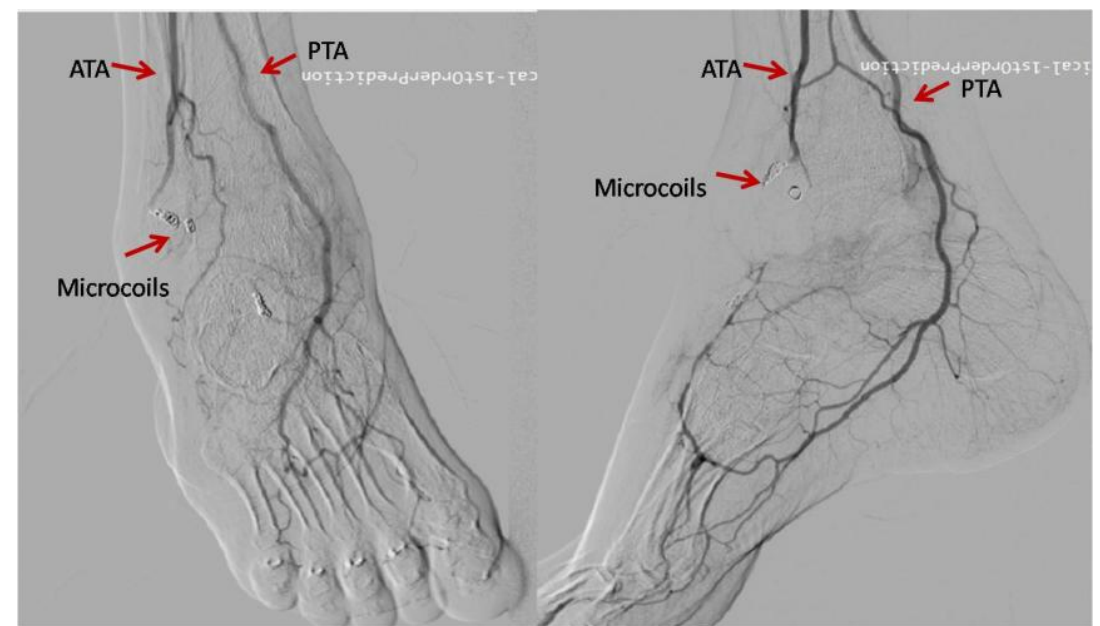

Figure (5): Check angiograms post microcoil embolisation revealing non-opacification of the pseudoaneurysm sac with good opacification of the distal vascular planter arch suggestive of successful procedure.

\section{DISCUSSION}

In the literature, tibial artery pseudoaneurysms have been described following blunt and penetrating trauma. They have also been seen following fracture reduction ${ }^{(2,4)}$. The various treatment methods describe are open surgery with simple ligation or interposition vein grafting, coil embolisation, ultrasoundguided thrombin injection ${ }^{(5,6)}$ and covered stent placements ${ }^{(\mathbf{7 , 8})}$. Advantages of endovascular technique is the reach to the sites which are surgically challenging (11) and rapid return to normal activity ${ }^{(\mathbf{1 2})}$.

Pseudoaneurysms forms when there is damage to the arterial wall which causes blood extravasation which is limited by surrounding fibrous tissue. As a result, there is chance of continuous expansion and rupture in pseudoaneurysm ${ }^{(9)}$. Diagnosis is usually made by Duplex ultrasound and arteriography ${ }^{(10)}$.

In our case, we decided to go for endovascular microcoil embolisation considering the age of the patient and suitable Doppler findings. Direct percutaneous thrombin injection was excluded due to risk of distal embolisation. Ultrasound guided compression was not a choice due to large size of the pseudoaneurysm sac.

\section{CONCLUSION}

Endovascular Microcoil embolisation is an effective treatment for this post- traumatic pseudoaneurysm of the anterior tibial artery. The procedure is less invasive than surgical resection, done under local anesthesia with minimal blood loss, enables continuation of distal blood flow with fast recovery period.

\section{Acknowledgement: None}

\section{Conflict of Interest: None}

\section{Source of Funding: None}

\section{REFERENCES}

1. Darius Aw KL, Tan CC, Ch'ng JK, et al. A case report of an anterior tibial artery pseudo-aneurysm open surgical management: a rare complication post total knee arthroplasty. Int J Surg Case Rep 2017;37:196e9.https://doi.org/10.1016/j.ijsc r.2017.06.037 PMid:28704746 PMCid:PMC5508493

2. Poposelli F, Hamdan A. Lower extremity aneurysms. In: Cronenwett J, Johnston K, editors. Rutherford's vascular surgery. 7th ed. Philadelphia: Saunders; 2010. p. 2126 e7.

3. Jones A, Kumar A. Successful stenting of iatrogenic anterior tibial artery pseudoaneurysm. EJVES Short Rep 2016;30:4-6.

https://doi.org/10.1016/j.ejvssr.2015.12.003 PMid:28856292 PMCid:PMC5573113

4. Suri T, Dabas V, Sural S, Dhal A. Pseudoaneurysm of the anterior tibial artery: a rare complication of proximal tibial Steinman pin insertion. Indian $\mathrm{J}$ Orthop 2011;45(2):178e80.https://doi.org/10.4103/0 
Vishal N. Bakare et.al. Successful endovascular management of large traumatic anterior tibial artery pseudoaneurysm.

019-5413.77140PMid:21430875

PMCid:PMC30511

5. Singh D, Ferero A. Traumatic pseudoaneurysm of the posterior tibial artery treated by endovascular coil embolization. Foot Ankle Spec 2013;6(1):54e8.https://doi.org/10.1177/1938 640012463053PMid:23074291

6. Kang S, Labropoulos N, Mansour M, Michelini M, Filliung D, Baubly M, et al. Expanded indications for ultrasound-guided thrombin injection of pseudoaneurysms. J Vasc Surg 2000;31: 289e98https://doi.org/10.1016/S07415214(00)90160-5

7. Spirito R, Trabattoni P, Pompilio G, Zoli S, Agrifoglio M, Biglioli P. Endovascular treatment of a post-traumatic tibial pseudoaneurysm and arteriovenous fistula: case report and review of the literature. $\mathbf{J}$ Vasc Surg 2007;45:1076e9. https://doi.org/10.1016/j.jvs.2006.12.038PM id: 1746680

8. De Troia A, Biasi L, Iazzolion L, Azzarone M, Tecchio T, Rossi C, et al. Endovascular stent grafting of posterior tibial artery pseudoaneurysm secondary to penetrating trauma: case report and review of the literature. Ann Vasc Surg 2014;28: 1789.e13e.https://doi.org/10.1016/j.avsg.20 14.02.013PMid:24530718
9. Casey PJ, LaMuraglia GM. Anastomotic Aneurysms. In: Rutherford RB, Cronenwett JL, Gloviczki P, eds. Vascular Surgery. Philadelphia: ElsevierSaunders; 2005;1:894902.

10. Han KJ, Won YY, Khang SY. Pseudoaneurysm after tibial nailing. Clin Orthop Relat Res. 2004;418:209212.https://doi.org/10.1097/00003086200401000-00035PMid:15043118

11. Redekop G, Marotta T, Weill A. Treatment of traumatic aneurysms and arteriovenous fistulas of the skull base by using endovascular stents. J Neurosurg. 2001;95:412-419.

https://doi.org/10.3171/jns.2001.95.3.0412P Mid:11565861

12. Thalhammer C, Kirchherr AS, Uhlich F, et al. Postcatheterization pseudoaneurysms and arteriovenous fistulas: repair with percutaneous implantation of endovascular covered stents. Radiology. 2000;214:127131.

https://doi.org/10.1148/radiology.214.1.r00j a04127PMid:10644111

How to cite this article: Bakare VN, Pattnaik S. Successful endovascular management of large traumatic anterior tibial artery pseudoaneurysm. International Journal of Science \& Healthcare Research. 2021; 6(2): 164-167. DOI: https:// doi.org/10.52403/ijshr.20210429 